\title{
Indications for invasive mediastinal staging for non-small cell lung cancer
}

\author{
Jules Lin, MD, ${ }^{\mathrm{a}}$ and Felix Fernandez, $\mathrm{MD}^{\mathrm{b}}$
}

\footnotetext{
From the ${ }^{\text {a Section }}$ of Thoracic Surgery, Department of Surgery, University of Michigan Medical Center, Ann Arbor, Mich; and ${ }^{\mathrm{b}}$ Division of Cardiothoracic Surgery, Department of Surgery, Emory University School of Medicine, Atlanta, Ga.

Received for publication May 6, 2018; revisions received July 7, 2018; accepted for publication July 10, 2018; available ahead of print Aug 23, 2018.

Address for reprints: Jules Lin, MD, Section of Thoracic Surgery, 1500 E. Medical Center Drive, 2120TC/5344, Ann Arbor, MI 48109-5344 (E-mail: juleslin@umich.edu).

J Thorac Cardiovasc Surg 2018;156:2319-24

$0022-5223 / \$ 36.00$

Copyright (c) 2018 by The American Association for Thoracic Surgery

https://doi.org/10.1016/j.jtcvs.2018.07.027
}

Accurate mediastinal staging remains a key component in the workup of patients with lung cancer, since treatment options and prognosis vary depending on the stage. While imaging studies continue to evolve, invasive mediastinal staging plays an important role in confirming nodal disease and ruling out false positives such as granulomatous lymph nodes. Thoracic surgeons must understand the advantages and disadvantages of each approach to mediastinal staging, the sensitivity and negative predictive value of different techniques, and the role of invasive mediastinal staging in the clinical decision making for different stages of lung cancer. While (EBUS-TBNA) has assumed a more prominent role over mediastinoscopy, it is important for surgeons to be facile with these techniques, the correct indications for their use, and when to proceed with mediastinoscopy despite a negative EBUS-TBNA if there continues to be high suspicion for mediastinal nodal disease. It is important that patients undergo appropriate mediastinal staging when indicated even when the planned treatment approach is stereotactic radiation or wedge resection because of poor pulmonary function or comorbidities, since the identification of stage III disease could alter the treatment approach.

\section{INVASIVE MEDIASTINAL STAGING FOR NON-SMALL CELL LUNG CANCER}

The indications to perform invasive mediastinal staging before a planned resection of a primary lung cancer depend on several factors. The first of these factors is the estimated prevalence of $\mathrm{N} 2$ metastases in the population, defined by clinical stage. The decision to perform invasive mediastinal staging is also affected by the performance of the imaging modality used for clinical staging, because both computed tomography (CT) and positron emission tomography (PET) are associated with significant false-positive and falsenegative rates. There will be more false-negative mediastinal lymph nodes when clinical staging is performed with CT as opposed to PET. ${ }^{1}$ The sensitivity and specificity of EBUSTBNA and mediastinoscopy for mediastinal lymph node metastases must also be considered. Because the sensitivity of a

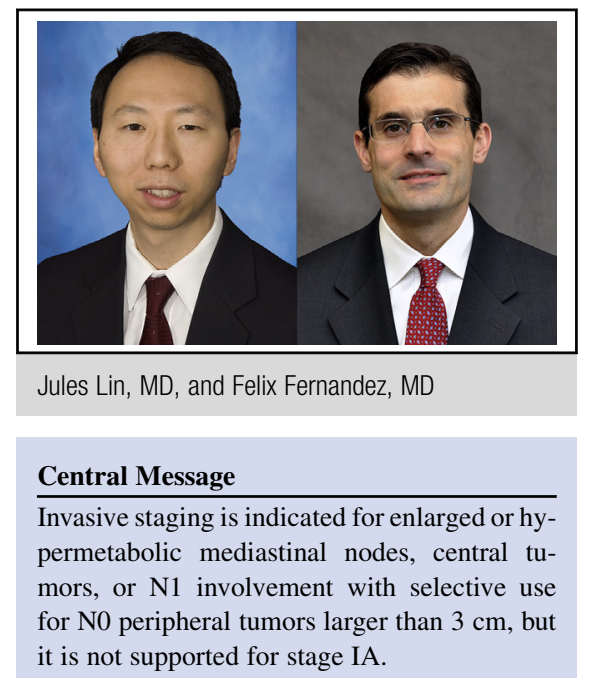

test is related to the prevalence of disease in the population, invasive mediastinal staging will be of greatest value in patients with a higher likelihood of N2 metastases. Another consideration is the presumed benefit of induction therapy versus postoperative adjuvant therapy for occult N2 disease.

In the absence of distant metastatic disease, staging of the mediastinal lymph nodes guides lung cancer treatment and determines prognosis. Despite the publication of lung cancer staging guidelines by the American College of Chest Physicians (ACCP), ${ }^{2}$ the European Society of Thoracic Surgeons (ESTS), ${ }^{3}$ and the National Comprehensive Cancer Network, ${ }^{4}$ there continues to be significant variability and underuse of invasive mediastinal staging. ${ }^{5}$ In a study of 15,316 patients in the Surveillance, Epidemiology, and End Results and Texas Cancer Registry Medicare-linked databases, only $21 \%$ of patients had guideline-consistent diagnostic evaluations, and $44 \%$ of patients never had mediastinal sampling. ${ }^{6}$ Patients with guideline-consistent care underwent fewer tests and had fewer complications.

The local expertise with EBUS-TBNA or mediastinoscopy is also a consideration. If the test is not performed reliably, it is also of little value. Whether a test is performed completely can be just as important as what staging tests are chosen. Detterbeck and colleagues ${ }^{7}$ have proposed a classification system for the thoroughness of mediastinal staging (complete, systematic, selective sampling, or poor).

\section{MEDIASTINOSCOPY}

Mediastinoscopy is the historical standard in mediastinal staging, and it provides access to lymph node stations 
TABLE 1. Invasive staging modalities

\begin{tabular}{|c|c|c|c|c|}
\hline Modality & Stations & $\begin{array}{c}\text { Sensitivity }^{2} \text { range } \\
\text { (Median) }\end{array}$ & $\begin{array}{l}\text { NPV }^{2} \text { range } \\
\text { (Median) }\end{array}$ & Comments \\
\hline Mediastinoscopy & $\begin{array}{l}2 \mathrm{R}, 2 \mathrm{~L}, 4 \mathrm{R}, 4 \mathrm{~L}, 7,10 \mathrm{R} \\
\quad \text { and } 10 \mathrm{~L}\end{array}$ & $32-92 \%(83)$ & $80-97 \%(90)$ & $\begin{array}{l}\text { Historical standard. Useful when high clinical suspicion and } \\
\text { EBUS/EUS negative or non-diagnostic. }\end{array}$ \\
\hline $\begin{array}{l}\text { Video } \\
\text { Mediastinoscopy }\end{array}$ & $\begin{array}{l}2 \mathrm{R}, 2 \mathrm{~L}, 4 \mathrm{R}, 4 \mathrm{~L}, 7,10 \mathrm{R} \\
\quad \text { and } 10 \mathrm{~L}\end{array}$ & $78-97 \%(89)$ & $91-99 \%(92)$ & Provides better visualization. \\
\hline $\begin{array}{l}\text { Extended } \\
\text { Mediastinoscopy }\end{array}$ & $\begin{array}{l}2 \mathrm{R}, 2 \mathrm{~L}, 4 \mathrm{R}, 4 \mathrm{~L}, 5,6,7 \\
10 \mathrm{R} \text {, and } 10 \mathrm{~L}\end{array}$ & $44-81 \%(71)$ & $89-95 \%(91)$ & $\begin{array}{l}\text { Provides access to stations } 5 \text { and } 6 \text { but not routinely } \\
\text { performed at most centers. }\end{array}$ \\
\hline TEMLA/VAMLA & $\begin{array}{l}2 \mathrm{R}, 2 \mathrm{~L}, 4 \mathrm{R}, 4 \mathrm{~L}, 5,6 \\
\quad 7,10 \mathrm{R} \text {, and } 10 \mathrm{~L}\end{array}$ & $94 \%(94)$ & $97-99 \%(98)$ & $\begin{array}{l}\text { Allows more extensive lymph node dissection but increased } \\
\text { risk of recurrent laryngeal nerve injury }\end{array}$ \\
\hline $\begin{array}{c}\text { Chamberlain } \\
\text { Procedure }\end{array}$ & 5 and 6 & $20-87 \%(71)$ & $89-96 \%(91)$ & Provides access to stations 5 and 6 \\
\hline VATS & $\begin{array}{l}2 \mathrm{R}, 4 \mathrm{R}, 5,6,7,8,9 \mathrm{~L}, 9 \mathrm{R} \\
10 \mathrm{R}, 10 \mathrm{~L}, 11 \mathrm{R}, 11 \mathrm{~L}\end{array}$ & $58-100 \%(99)$ & $88-100 \%(96)$ & Provides unilateral access to wide range of lymph nodes. \\
\hline EBUS-TBNA & $\begin{array}{l}2 \mathrm{R}, 2 \mathrm{~L}, 4 \mathrm{R}, 4 \mathrm{~L}, 7,10 \mathrm{R}, 10 \mathrm{~L} \\
\quad 11 \mathrm{R}, 11 \mathrm{~L}, 12 \mathrm{R}, 12 \mathrm{~L}\end{array}$ & $45-100 \%(96)$ & $68-100 \%(83)$ & $\begin{array}{l}\text { Preferred initial approach when expertise available. At least } \\
3 \text { passes per lymph node or rapid onsite evaluation. } \\
\text { Diagnostic cytology should show presence of } \\
\text { lymphocytes. }\end{array}$ \\
\hline EUS-FNA & $5,7,8,9$ & $14-100 \%(96)$ & $10-100 \%(90)$ & $\begin{array}{l}\text { Allows access to stations } 8 \text { and } 9 \text { and increases sensitivity } \\
\text { when added to EBUS-TBNA. }\end{array}$ \\
\hline
\end{tabular}

NPV, Negative predictive value; EBUS, endobronchial ultrasound; $E U S$, endoscopic ultrasound; TEMLA, transcervical extended mediastinal lymphadenectomy; VAMLA, videoassisted mediastinal lymphadenectomy; VATS, video-assisted thoracoscopic surgery; EBUS-TBNA, endobronchial ultrasound-transbronchial needle aspiration; EUS-FNA, endoscopic ultrasound-fine needle aspiration.

2R, 2L, 4R, 4L, 7, 10R, and 10L (Table 1). Guidelines from the ACCP and ESTS recommend that lymph nodes should be biopsied from at least five mediastinal node stations. ${ }^{2,3}$ It is a minimally-invasive surgical procedure performed under general anesthesia. The risk of hoarseness from recurrent laryngeal nerve injury and bleeding are low when performed by an experienced surgeon. Wei and colleagues reported results from 1,970 mediastinoscopies and found a sensitivity of $90 \%$ with a negative predictive value (NPV) of $92 \%$, morbidity of $1.3 \%$, and significant bleeding in $0.25 \%{ }^{8}$ Procedures were performed as an outpatient in $96.1 \%$. Mediastinoscopy may be useful and preferred in certain situations where mobilization of the proximal airway complements subsequent intrathoracic airway reconstruction. Surgeons should also be aware of situations where mediastinoscopy carries greater risk such as redo procedures and mediastinal fibrosis from radiation treatment.

Extended mediastinoscopy continues the dissection between the anterior aspect of the left innominate vein and the sternum over the aortic arch at the origin of the innominate artery, allowing additional access to stations 5 and 6. A Chamberlain procedure (anterior mediastinotomy), CT-guided biopsy, or a left thoracoscopic approach are also alternatives to biopsy stations 5 and 6 . Transcervical extended mediastinal lymphadenectomy (TEMLA) and video-assisted mediastinal lymphadenectomy (VAMLA) allow a more extensive bimanual lymph node dissection with a sensitivity of 0.96 and NPV of
0.99 but have an increased risk of recurrent laryngeal nerve injury. ${ }^{9,10}$

\section{ENDOBRONCHIAL ULTRASOUND WITH FINE NEEDLE ASPIRATION}

EBUS-TBNA (Figure 1) is an endoscopic procedure that can be performed with sedation and topical anesthesia and allows biopsies of stations $11 \mathrm{R}, 11 \mathrm{~L}, 12 \mathrm{R}$, and $12 \mathrm{~L}$ in addition to the $2 \mathrm{R}, 2 \mathrm{~L}, 4 \mathrm{R}, 4 \mathrm{~L}, 7,10 \mathrm{R}$, and $10 \mathrm{~L}$ lymph nodes accessible by mediastinoscopy (Table 1). Biopsies of small

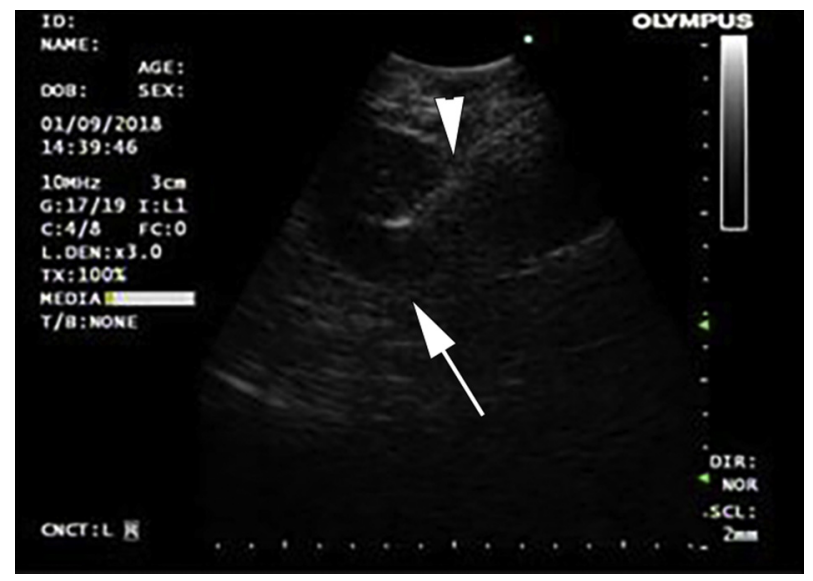

FIGURE 1. Endobronchial ultrasound-guided fine needle aspiration (arrowhead) of a precarinal lymph node (arrow) was positive for adenocarcinoma. 
lymph nodes $<5 \mathrm{~mm}$ may be limited. Overall costs are less than mediastinoscopy. Yasufuku and colleagues performed a prospective trial comparing EBUS-TBNA and mediastinoscopy for staging of potentially resectable lung cancer. EBUS-TBNA was followed by mediastinoscopy in all 153 patients. ${ }^{11}$ An average of three lymph node stations were sampled per patient by EBUS-TBNA while four stations were sampled on average by mediastinoscopy. Agreement between EBUS-TBNA and mediastinoscopy results were excellent at $91 \%$ with a Kappa of 0.8 (95\% CI 0.7-0.9). The sensitivity, NPV, and accuracy for mediastinoscopy were $79 \%, 90 \%$, and $93 \%$ compared to EBUS-TBNA at $81 \%, 91 \%$, and $93 \%$. In centers with expertise, EBUSTBNA can achieve similar results to mediastinoscopy. While the sensitivity of $79 \%$ and $81 \%$ was relatively low, this can likely be explained by the higher percentage of clinical stage I lung cancers (59\%) in the study cohort with a lower prevalence of $\mathrm{N} 2$ disease resulting in a lower sensitivity. Studies have also shown increased accuracy with a higher number of aspirations per lymph node, and at least three passes or rapid-on-site evaluation by cytology are recommended. $^{12}$

A randomized trial of 241 patients comparing mediastinoscopy in 118 patients to EBUS-TBNA and endoscopic ultrasound-fine needle aspiration (EUS-FNA) followed by mediastinoscopy, if negative, in 123 patients has been reported in a European trial by Annema and colleagues. ${ }^{13}$ Inclusion criteria included patients with potentially resectable lung cancer with either clinically positive mediastinal or hilar lymph nodes or central tumors. The sensitivity of 94\% (95\% CI 0.85-0.98) in the EBUS-TBNA/EUS-FNA group was significantly higher than mediastinoscopy with a sensitivity of $79 \%$ (95\% CI $0.66-0.88)$. The NPV was $93 \%$ and $86 \%$, respectively. A subgroup analysis of patients with clinically positive N2/N3 disease on PETCT showed a sensitivity of $86 \%$ for EBUS-TBNA/EUSFNA which increased to $97 \%$ when mediastinoscopy was added if EBUS-TBNA/EUS-FNA was negative. ${ }^{14}$
Another randomized trial by $\mathrm{Um}$ and colleagues comparing EBUS-TBNA to mediastinoscopy reported a sensitivity of $88 \%$ (95\% CI 0.78-0.94) for EBUS-TBNA and $81 \%$ (95\% CI $0.78-0.94)$ for mediastinoscopy. ${ }^{15}$ These results demonstrate that endosonographic biopsies followed by mediastinoscopy, if negative, may be the preferred strategy for mediastinal staging when N2 disease is suspected.

EBUS-TBNA should be followed by mediastinoscopy when cytology is non-diagnostic with the absence of lymphocytes or there is a high suspicion of N2 disease on CT or PET. When the suspicious lymph nodes are inaccessible by EBUS-TBNA, a Chamberlain procedure (anterior mediastinotomy) or a left thoracoscopic approach should be performed to sample stations 5 and 6 while station 7, 8, and 9 lymph nodes can be biopsied by EUS-FNA. A meta-analysis by Korevaar and colleagues evaluated the combination of EBUS-TBNA and EUS-FNA for mediastinal staging and found a sensitivity of $83 \%$ and an NPV of $91 \%$ with the addition of EUS-FNA leading to a mean increase in sensitivity of $12 \% .{ }^{16}$ Future advances in endoscopic techniques including impedance ultrasonography may further improve the sensitivity and specificity of mediastinal staging. Ultrasonographic criteria including the short axis, characteristics of the central hilum, heterogeneity, shape, contour, and evidence of necrosis may also be useful in predicting the likelihood of malignancy.

\section{CLINICAL STAGE IIIA (T1-2N2; T3N1; T4N0-1)}

The most straightforward scenario is defined by that of clinical stage IIIA disease. This is defined by either mediastinal lymph node enlargement $(>1 \mathrm{~cm}$ on short axis) with or without increased uptake of F-fluoro-2-deoxy-d-glucose (FDG) on PET scan or increased FDG uptake in mediastinal lymph nodes which are not enlarged on CT (Figure 2). Invasive mediastinal staging is indicated in these scenarios as the pre-test probability of $\mathrm{N} 2$ metastases is high. However, presumed nodal metastases must be confirmed histologically.

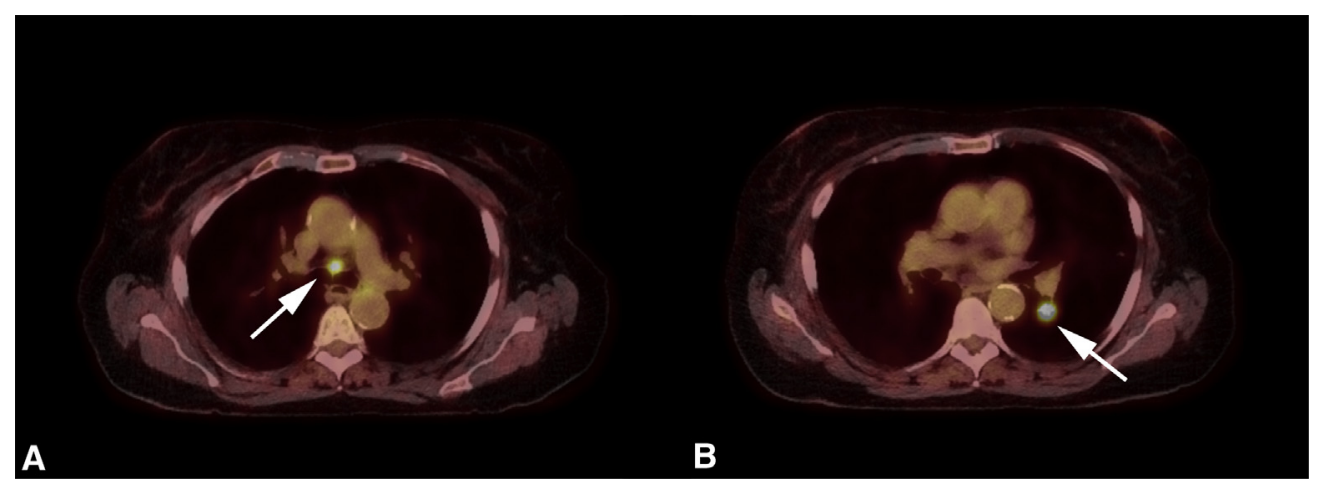

FIGURE 2. A, Hypermetabolic precarinal lymph node (arrow) in a patient with single station stage IIIA lung adenocarcinoma. B, FDG-avid left lower lobe lung adenocarcinoma (arrow). 
TABLE 2. Recommendations from lung cancer staging guidelines

\begin{tabular}{|c|c|c|c|}
\hline Clinical stage & $\mathbf{A C C P}^{2}$ & ESTS $^{3}$ & $\mathrm{NCCN}^{4}$ \\
\hline $\begin{array}{r}\text { Peripheral IA } \\
(\mathrm{T} 1 \mathrm{abcN} 0)\end{array}$ & $\begin{array}{l}\text { Invasive pre-operative evaluation of } \\
\text { mediastinal nodes not required } \\
\text { (Grade 2B) }\end{array}$ & $\begin{array}{l}\text { Proceed directly to surgery (lung } \\
\text { resection) }\end{array}$ & $\begin{array}{l}\text { Pre-resection pathologic mediastinal } \\
\text { evaluation optional for solid tumors } \\
<1 \mathrm{~cm} \text { and non-solid tumors }<3 \mathrm{~cm} \text { due } \\
\text { to low likelihood of positive nodes }\end{array}$ \\
\hline $\begin{array}{l}\text { Central IA (T1abcN0) } \\
\text { IB (T2a, N0) } \\
\text { II (T1abc-T2abN1; } \\
\quad \text { T2bN0, T3N0) }\end{array}$ & $\begin{array}{l}\text { Intermediate suspicion N2/3 with } \\
\text { central tumor or N1 nodes, invasive } \\
\text { staging of mediastinum } \\
\text { recommended (Grade 1C) }\end{array}$ & $\begin{array}{l}\text { Central lesion or suspected N1, invasive } \\
\text { staging recommended }\end{array}$ & $\begin{array}{l}\text { Pathologic mediastinal evaluation } \\
\text { recommended }\end{array}$ \\
\hline $\begin{array}{l}\text { IIIA (T1-2N2; } \\
\text { T3N1; T4N0-1) }\end{array}$ & $\begin{array}{l}\text { Discrete mediastinal lymph node } \\
\text { enlargement or PET uptake, } \\
\text { invasive staging of mediastinum } \\
\text { recommended (Grade 1C). With } \\
\text { extensive mediastinal infiltration, } \\
\text { radiographic assessment usually } \\
\text { sufficient without invasive } \\
\text { confirmation (Grade 2C) }\end{array}$ & Invasive staging recommended & $\begin{array}{l}\text { Pathologic mediastinal evaluation } \\
\text { recommended }\end{array}$ \\
\hline \multirow[t]{2}{*}{$\begin{array}{l}\text { Other } \\
\text { Recommendations }\end{array}$} & $\begin{array}{l}\text { Needle technique (EBUS-TBNA, } \\
\text { EUS-FNA or combined EBUS/ } \\
\text { EUS-FNA) is suggested over } \\
\text { surgical staging as best first test } \\
\text { (Grade 2B) }\end{array}$ & $\begin{array}{l}\text { Endosonography (EBUS/EUS) with } \\
\text { FNA first choice when available }\end{array}$ & $\begin{array}{l}\text { Least invasive biopsy with the highest } \\
\text { yield is preferred. }\end{array}$ \\
\hline & $\begin{array}{l}\text { Where clinical suspicion of } \\
\text { mediastinal node involvement } \\
\text { remains high after negative result } \\
\text { using needle technique, surgical } \\
\text { staging should be performed }\end{array}$ & $\begin{array}{l}\text { With enlarged or PET-positive } \\
\text { mediastinal nodes, mediastinoscopy } \\
\text { indicated if endosonographic biopsy } \\
\text { (EBUS/EUS) negative }\end{array}$ & $\begin{array}{l}\text { Evaluation of the subcarinal and } \\
\text { contralateral lymph nodes important } \\
\text { even when employing EBUS +/- EUS. }\end{array}$ \\
\hline
\end{tabular}

$\overline{A C C P}$, American College of Chest Physicians; ESTS, European Society of Thoracic Surgeons; NCCN, National Comprehensive Cancer Network; PET, positron emission tomography; EBUS-TBNA, endobronchial ultrasound-transbronchial needle aspiration; EUS-FNA, endoscopic ultrasound-fine needle aspiration; $F N A$, fine needle aspiration; $E B U S$, endobronchial ultrasound; EUS, endoscopic ultrasound.

This is necessary because PET and CT have high false positive rates and relatively low sensitivity and specificity. In this scenario, EBUS-TBNA is preferred over mediastinoscopy as the first test to invasively stage the mediastinum. If the EBUS-TBNA is negative, a mediastinoscopy should be performed if suspicion for positive $\mathrm{N} 2$ disease remains high. This is a less invasive approach and reserves mediastinoscopy for potential restaging of the mediastinum following administration of induction therapy. The sensitivity of EBUS-TBNA has been shown to be lower at $67 \%$ after induction therapy. ${ }^{17}$

\section{CLINICAL STAGE II (T1abc-T2abN1; T2bN0, T3N0)}

The next scenario to consider is that of patients with central lung cancers or with clinically positive N1 lymph nodes. It is often difficult to discern between central tumors and enlarged N1 lymph nodes. These patients most often are classified as clinical stage II. The false negative rate for PET and CT approaches $25 \%$ for mediastinal lymph node disease in this setting. ${ }^{18-20}$ Given the high prevalence of $\mathrm{N} 2$ disease in this group of patients, invasive staging of the mediastinum with EBUS-TBNA or mediastinoscopy is indicated. EBUS-TBNA (with or without EUS-FNA) is recommended as the first choice if the expertise is available given its similar performance and decreased invasiveness.

\section{CLINICAL STAGE IA (PERIPHERAL T1abcN0)}

For clinical stage IA lung cancer, the false negative rate of a CT scan for N2 disease is approximately $10 \% .{ }^{21}$ The performance of PET/CT is better with a false negative rate in the range of $3-6 \%{ }^{18-20,22}$ Wang and colleagues have published a meta-analysis examining the NPV of PET/CT for occult N2 disease in clinical stage I lung cancer. $^{23}$ This meta-analysis included 10 studies with a cumulative total of 1122 patients. The negative predictive value of PET/CT for mediastinal lymph node metastases in clinical IA and IB lung cancer was $94 \%$ and $89 \%$, respectively. Cerfolio and colleagues have previously examined the performance of mediastinoscopy and EBUS-TBNA for N2 disease in clinical stage IA lung cancer. ${ }^{22}$ The prevalence of $\mathrm{N} 2$ disease in the stage IA lung cancer population in this study was approximately $5 \%$, and the sensitivity of mediastinoscopy was $60 \%$, which was quite good given that the sensitivity of a test is related to the prevalence of disease 
in a population. With the observed prevalence and sensitivity, the number needed to treat to detect one positive $\mathrm{N} 2$ lymph node was 33 patients.

Therefore, invasive mediastinal staging can likely be omitted for patients with clinical stage IA lung cancer based on PET/CT staging. The prevalence of $\mathrm{N} 2$ disease is expected to be low in this setting while the sensitivity of mediastinoscopy and/or EBUS-TBNA is only moderate. The expected number to treat to detect one N2 nodal metastases would be expected to be approximately 25 to 40 patients dependent on the estimates of prevalence of N2 disease and sensitivity of mediastinoscopy or EBUS-TBNA that are used. In a prior decision analysis which investigated the utility of mediastinoscopy for clinical stage IA lung cancer in patients staged with PET scans, Meyers and colleagues determined that if prevalence of $\mathrm{N} 2$ disease is $>10 \%$, mediastinoscopy may lengthen life at a cost of $<\$ 100,000$ per life year. ${ }^{24}$ However, below this prevalence threshold, mediastinoscopy was not cost effective. In clinical stage IA lung cancer, the prevalence of $\mathrm{N} 2$ disease does not reach this threshold. While preoperative mediastinal staging is not recommended, systematic nodal sampling at the time of lung resection is still essential for appropriate pathologic staging, even in patients who are cNO.

\section{CLINICAL STAGE IB (T2AN0)}

More uncertain is whether invasive mediastinal staging is indicated for clinical stage IB lung cancer. Risk factors for occult N2 metastases include larger tumor size, central location, adenocarcinoma, lymphovascular invasion, and a higher standardized uptake value (SUV) on PET. $^{25}$ The performance of PET/CT may be worse in these scenarios with more false negative results. As previously demonstrated in the meta-analysis by Wang and colleagues occult $\mathrm{N} 2$ disease is found in up to $11 \%$ of patients with cT2N0 lung cancer after PET/CT staging. ${ }^{23}$ With a higher prevalence of $\mathrm{N} 2$ disease, invasive mediastinal staging is of greater utility. Contemporary clinical practice guidelines recommend invasive mediastinal staging in these patients. ${ }^{2,3}$

One of us (FF) has previously conducted a study to examine the utility of mediastinoscopy in clinical stage I lung cancers at increased risk for mediastinal lymph node metastases. ${ }^{26}$ The objective was to determine the prevalence of occult $\mathrm{N} 2$ metastases in patients with clinical T2N0 or clinical T1N0 lung cancer with an SUV $>10$ by PET/CT in order to determine if routine mediastinoscopy was justified in this group of patients. Ninety patients with lung cancer were prospectively studied with 81 patients clinical stage T2N0 and 9 patients T1N0 with an SUV $>10$. Of the 275 lymph node stations sampled with mediastinoscopy in these 90 patients, there was one positive $\mathrm{N} 2$ node. Therefore, the rate of positive mediastinoscopy was $1.1 \%$. Lung
TABLE 3. Overall recommendations for invasive mediastinal staging

\begin{tabular}{|c|c|}
\hline Clinical stage & Recommendation \\
\hline Peripheral IA (T1abcN0) & $\begin{array}{l}\text { Peripheral stage IA, pre-operative invasive } \\
\text { mediastinal staging not required }\end{array}$ \\
\hline Peripheral IB (T2a, N0) & $\begin{array}{l}\text { Selective use of invasive mediastinal } \\
\text { staging based on surgeon judgement and } \\
\text { risk factors for occult N2 metastases } \\
\text { (adenocarcinoma, lymphovascular } \\
\text { invasion, and higher PET SUV) }\end{array}$ \\
\hline $\begin{array}{l}\text { Central IA (T1abcN0) } \\
\text { Central IB (T2a, N0) } \\
\text { II (T1abc-T2abN1; } \\
\quad \text { T2bN0, T3N0) }\end{array}$ & $\begin{array}{l}\text { Larger tumors }(>\mathrm{T} 2 \mathrm{a}) \text {, central tumors, or } \\
\text { suspected } \mathrm{N} 1 \text { disease, invasive staging of } \\
\text { mediastinum recommended }\end{array}$ \\
\hline $\begin{array}{l}\text { IIIA (T1-2N2; T3N1; } \\
\text { T4N0-1) }\end{array}$ & $\begin{array}{l}\text { With high suspicion of mediastinal lymph } \\
\text { node enlargement or PET uptake, } \\
\text { invasive staging of the mediastinum } \\
\text { recommended }\end{array}$ \\
\hline $\begin{array}{l}\text { Other } \\
\text { Recommendations }\end{array}$ & $\begin{array}{l}\text { Endoscopic biopsies (EBUS-TBNA, } \\
\text { EUS-FNA or combined EBUS-TBNA/ } \\
\text { EUS-FNA) is preferred over surgical } \\
\text { staging when available and should } \\
\text { include at least three passes per lymph } \\
\text { node or rapid-on-site evaluation } \\
\text { When suspicion of mediastinal node } \\
\text { involvement remains high after negative } \\
\text { needle aspiration, surgical staging should } \\
\text { be performed } \\
\text { Complete evaluation including subcarinal } \\
\text { and contralateral lymph nodes important } \\
\text { regardless of technique used } \\
\text { (mediastinoscopy, EBUS-TBNA, or } \\
\text { EUS-FNA). }\end{array}$ \\
\hline
\end{tabular}

PET, Positron emission tomography; $S U V$, standardized uptake value; $E B U S-T B N A$, endobronchial ultrasound-transbronchial needle aspiration; EUS-FNA, endoscopic ultrasound-fine needle aspiration.

cancer resection was performed in 86 of these patients while 4 had N2 disease detected at the time of surgery. Therefore, the total rate of $\mathrm{N} 2$ upstaging was $5.6 \%$. Only $4.4 \%$ of positive lymph nodes were accessible by mediastinoscopy as there was one positive station 5 lymph node. The NPV of mediastinoscopy after PET/CT was $95 \%$, only a $1 \%$ improvement over PET/CT alone, and the sensitivity of mediastinoscopy after a negative PET/CT was only $25 \%$ due to the low prevalence of disease. Therefore, the routine use of mediastinoscopy in patients with clinical N0 lung cancer may not be warranted, even if the tumor is clinical stage IB or intensely hypermetabolic. We advocate selective use of invasive mediastinal staging based on surgeon judgement.

\section{CONCLUSIONS}

Accurate mediastinal staging remains a critical component in the workup of patients with lung cancer since 
treatment options and prognosis vary depending on the stage. Thoracic surgeons must understand the advantages and disadvantages of each approach to mediastinal staging and the role of invasive mediastinal staging in clinical decision-making. Invasive mediastinal staging is recommended in several groups of lung cancer patients defined by their clinical stage (Tables 2 and 3$)^{2-4}$ If local expertise is available, the preferred strategy is to begin with EBUS-TBNA-guided biopsies followed by mediastinoscopy if non-diagnostic or there continues to be high suspicion for mediastinal nodal disease. Invasive staging is most clearly indicated in patients with mediastinal lymph nodes that are $>1 \mathrm{~cm}$ or hypermetabolic on PET. In patients with central tumors or clinical N1 lymph node involvement on PET or CT, invasive staging is also indicated. For peripheral tumors greater than $3 \mathrm{~cm}$ in size that are clinical N0, the data is not conclusive. Invasive staging may benefit some but not all of these clinically diverse patients. More studies are needed in this subgroup of patients, and we recommend selective application of invasive staging at present. Finally, the data do not support the routine use of invasive mediastinal staging for clinical stage IA lung cancers.

\section{Conflict of Interest Statement}

Dr Lin serves as a Surgical Site Mentor/Proctor for Intuitive Surgical outside the submitted work. All other authors have nothing to disclose with regard to commercial support.

\section{References}

1. De Wever W, Ceyssens S, Mortelmans L, Stroobants S, Marchal G, Bogaert J, et al. Additional value of PET-CT in the staging of lung cancer: comparison with CT alone, PET alone and visual correlation of PET and CT. Eur Radiol. 2007; 17:23-32.

2. Silvestri GA, Gonzalez AV, Jantz MA, Margolis ML, Gould MK, Tanoue LT, et al. Methods for staging non-small cell lung cancer: Diagnosis and management of lung cancer, 3rd ed: American College of Chest Physicians evidence-based clinical practice guidelines. Chest. 2013;143:e211S-50S.

3. De Leyn P, Dooms C, Kuzdzal J, Lardinois D, Passlick B, Rami-Porta R, et al. Revised ESTS guidelines for preoperative mediastinal lymph node staging for non-small-cell lung cancer. Eur J Cardiothorac Surg. 2014;45:787-98.

4. Ettinger DS, Wood DE, Aisner DL, Akerley W, Bauman J, Chirieac LR, et al. Non-Small Cell Lung Cancer, Version 5.2017, NCCN Clinical Practice Guidelines in Oncology. J Natl Compr Canc Netw. 2017;15:504-35.

5. Thornblade LW, Wood DE, Mulligan MS, Farivar AS, Hubka M, Costas KE, et al. Variability in invasive mediastinal staging for lung cancer: A multicenter regional study. J Thorac Cardiovasc Surg. 2018;155:2658-71.e1.

6. Ost DE, Niu J, Elting LS, Buchholz TA, Giordano SH. Quality gaps and comparative effectiveness in lung cancer staging and diagnosis. Chest. 2014;145:331-45.

7. Detterbeck F, Puchalski J, Rubinowitz A, Cheng D. Classification of the thoroughness of mediastinal staging of lung cancer. Chest. 2010;137:436-42.

8. Wei B, Bryant AS, Minnich DJ, Cerfolio RJ. The safety and efficacy of mediastinoscopy when performed by general thoracic surgeons. Ann Thorac Surg. 2014;97:1878-83; discussion 1883-4.
9. Call S, Obiols C, Rami-Porta R, Trujillo-Reyes JC, Iglesias M, Saumench R, et al. Video-Assisted Mediastinoscopic Lymphadenectomy for Staging Non-Small Cell Lung Cancer. Ann Thorac Surg. 2016;101:1326-33.

10. Zielinski M. Transcervical extended mediastinal lymphadenectomy: results of staging in two hundred fifty-six patients with non-small cell lung cancer. $J$ Thorac Oncol. 2007;2:370-2.

11. Yasufuku K, Pierre A, Darling G, de Perrot M, Waddell T, Johnston M, et al. A prospective controlled trial of endobronchial ultrasound-guided transbronchial needle aspiration compared with mediastinoscopy for mediastinal lymph node staging of lung cancer. J Thorac Cardiovasc Surg. 2011;142: 1393-1400 e1391.

12. Lee HS, Lee GK, Lee HS, Kim MS, Lee JM, Kim HY, et al. Real-time endobronchial ultrasound-guided transbronchial needle aspiration in mediastinal staging of non-small cell lung cancer: how many aspirations per target lymph node station? Chest. 2008;134:368-74.

13. Annema JT, van Meerbeeck JP, Rintoul RC, Dooms C, Deschepper E, Dekkers OM, et al. Mediastinoscopy vs endosonography for mediastinal nodal staging of lung cancer: a randomized trial. JAMA. 2010;304:2245-52.

14. Tournoy KG, Keller SM, Annema JT. Mediastinal staging of lung cancer: novel concepts. Lancet Oncol. 2012;13:e221-9.

15. Um SW, Kim HK, Jung SH, Han J, Lee KJ, Park HY, et al. Endobronchial ultrasound versus mediastinoscopy for mediastinal nodal staging of non-small-cell lung cancer. J Thorac Oncol. 2015;10:331-7.

16. Korevaar DA, Crombag LM, Cohen JF, Spijker R, Bossuyt PM, Annema JT. Added value of combined endobronchial and oesophageal endosonography for mediastinal nodal staging in lung cancer: a systematic review and meta-analysis. Lancet Respir Med. 2016;4:960-8.

17. Szlubowski A, Kuzdzal J, Kolodziej M, Soja J, Pankowski J, Obrochta A, et al. Endobronchial ultrasound-guided needle aspiration in the non-small cell lung cancer staging. Eur J Cardiothorac Surg. 2009;35:332-5; discussion 335-6.

18. Pozo-Rodriguez F, Martin de Nicolas JL, Sanchez-Nistal MA, Maldonado A, Garcia de Barajas S, Calero-Garcia R, et al. Accuracy of helical computed tomography and $[18 \mathrm{~F}]$ fluorodeoxyglucose positron emission tomography for identifying lymph node mediastinal metastases in potentially resectable non-small-cell lung cancer. J Clin Oncol. 2005; 23:8348-56.

19. Serra M, Cirera L, Rami-Porta R, Bastus R, Gonzalez S, Simo M, et al. Routine positron emission tomography (PET) and selective mediastinoscopy is as good as routine mediastinoscopy to rule out N2 disease in non-small cell lung cancer (NSCLC). J Clin Oncol. 2006;24:371S.

20. Verhagen AF, Bootsma GP, Tjan-Heijnen VC, van der Wilt GJ, Cox AL, Brouwer MH, et al. FDG-PET in staging lung cancer: how does it change the algorithm? Lung Cancer. 2004;44:175-81.

21. Freixinet Gilart J, Garcia PG, de Castro FR, Suarez PR, Rodriguez NS, de Ugarte AV. Extended cervical mediastinoscopy in the staging of bronchogenic carcinoma. Ann Thorac Surg. 2000;70:1641-3.

22. Cerfolio RJ, Bryant AS, Eloubeidi MA. Routine mediastinoscopy and esophageal ultrasound fine-needle aspiration in patients with non-small cell lung cancer who are clinically N2 negative: a prospective study. Chest. 2006; 130:1791-5.

23. Wang J, Welch K, Wang L, Kong FM. Negative predictive value of positron emission tomography and computed tomography for stage T1-2N0 non-small-cell lung cancer: a meta-analysis. Clin Lung Cancer. 2012;13:81-9.

24. Meyers BF, Haddad F, Siegel BA, Zoole JB, Battafarano RJ, Veeramachaneni N, et al. Cost-effectiveness of routine mediastinoscopy in computed tomographyand positron emission tomography-screened patients with stage I lung cancer. J Thorac Cardiovasc Surg. 2006;131:822-9; discussion 822-9.

25. Bryant AS, Cerfolio RJ, Klemm KM, Ojha B. Maximum standard uptake value of mediastinal lymph nodes on integrated FDG-PET-CT predicts pathology in patients with non-small cell lung cancer. Ann Thorac Surg. 2006;82:417-22; discussion 422-3.

26. Fernandez FG, Kozower BD, Crabtree TD, Force SD, Lau C, Pickens A, et al. Utility of mediastinoscopy in clinical stage I lung cancers at risk for occult mediastinal nodal metastases. J Thorac Cardiovasc Surg. 2015;149:35-41. 42.e31. 